Revista Mexicana de Economía y Finanzas Nueva Época, Vol. 13 No. 4, (2018), pp. 507-523

DOI: http://dx.doi.org/10.21919/remef.v13i4.336

\title{
Envy and Inequality in Income and Wealth in a Dynamic General Equilibrium Theory
}

Prof. Wei-Bin Zhang ${ }^{1}$

Ritsumeikan Asia Pacific University, Japan

(Primera recepción: 8/noviembre/2017, última recepción: 11/abril/2018, aceptado: 15/junio/2018)

\section{Abstract}

The purpose of this study is to deal with interactions between envy, economic growth and income and wealth distribution in a heterogeneous-household growth model with economic structure. With regards to envy and its impact, this study is influenced by the economic model with envy by Gershman (2014). We deal with the (destructive) role of envy on labor supply, time distribution between labor and destructive activities, and wealth and income distribution. The model is framed in a general dynamic general equilibrium theory. The economic structure composes of one consumer goods sector and one capital goods sector. The motion is described by a set of differential equations. We simulate the movement of a three-group economy with endogenous envy. We carry out comparative dynamic analysis to show how envy and other exogenous changes affect transitory processes and equilibrium structure of the economy.

JEL Classification: D31, O41, Y80, Z13

Keywords: envy, destructive activities, neoclassical growth theory, wealth accumulation, Walrasian general equilibrium theory, income and wealth distribution

\section{Envidia y Desigualdad en el Ingreso y Riqueza en una Teoría del Equilibrio General Dinámico}

\section{Resumen}

El objetivo de este estudio es abordar las interacciones entre la envidia, el crecimiento económico y la distribución del ingreso y la riqueza en un modelo de crecimiento heterogéneo de los hogares con estructura económica. En cuanto a la envidia y su impacto, este estudio está influenciado por el modelo económico con envidia de Gershman (2014). Nos ocupamos del papel (destructivo) de la envidia en la oferta de mano de obra, la distribución del tiempo entre el trabajo y las actividades destructivas, y la distribución de la riqueza y el ingreso. El modelo se enmarca en una teoría general del equilibrio general dinámico. La estructura económica se compone de un sector de bienes de consumo y un sector de bienes de capital. El movimiento se describe mediante un conjunto de ecuaciones diferenciales. Simulamos el movimiento de una economía de tres grupos con envidia endógena. Realizamos análisis dinámicos comparativos para mostrar cómo la envidia y otros cambios exógenos afectan los procesos transitorios y la estructura de equilibrio de la economía.

Clasificación JEL: D31, O41, Y80, Z13

Palabras clave: envidia, actividades destructivas, teoría del crecimiento neoclásico, acumulación de riqueza; teoría del equilibrio general de Walras, ingresos y distribución de la riqueza

\footnotetext{
${ }^{1}$ Prof. Wei-Bin Zhang

Ritsumeikan Asia Pacific University 1-1 Jumo_jibaru, Beppu-Shi, Oita-ken874-8577 Japan (Home Tel: 0977-73-9787; Office Tel: 0977-78-1020; Fax: 0977-78-1123; E-mail: wbz1@apu.ac.jp)

Acknowledgements: The author is grateful to the constructive comments of Prof. Ricardo J. Mendoza
} 
508 REMEF (The Mexican Journal of Economics and Finance)

Envy and Inequality in Income and Wealth in a Dynamic General Equilibrium Theory

\section{Introduction}

In The Wealth of Nations, Adam Smith (1776) introduced the impact of envy on wealth distribution as follows: "The affluence of the rich excites the indignation of the poor, who are often both driven by want, and prompted by envy, to invade his possessions." Although envy and constrictive and destructive activities associated with envy have been examined from different perspectives by scholars in varied fields, it may be argued that there are only a few economic studies which formally examine dynamics of envy and its impact on inequalities in income and wealth over time.

This study deals with interactions between envy and economic growth in dynamic general equilibrium theory. There are some studies on the economics of envy. Normative aspects of envy were examined by economists in welfare economics long time ago (Varian, 1974; Baumol, 1987). Behavioral implications of envy are studied by, for instance, Banerjee (1990) and Kirchsteiger (1995). Brennan (1973) examines how non-altruistic individuals can be motivated by envy to promote redistribution programs as the individuals value reducing the rich's consumption. Banerjee (1990) examines how progressive taxation may be promoted to correct the distortions created by envy. Mui (1995) analyzes the economics of envy in the standard economic choice framework. The model examines how agents' innovating, retaliating, sabotaging, and sharing behavior are determined by propensities for envy and other factors. As far as introduction of envy into formal economic modelling is concerned, this study is specially inspirited by a recent publication by Gershman (2014). In the Gershman model, if there are scarce investment opportunities, large inequalities, and insecure property rights, the economic system may be located in a fear equilibrium where richer agents underinvest because of fearing destructive factors due to envy of the poor. Otherwise, the economy follows the traditional "keeping up with the Joneses" competition where envy is satisfied with high efforts. This study emphasizes destructive side of envy and examines how destructive activities interact with dynamics of growth and income and wealth distribution.

This paper studies interactions between envy and economic growth in a general economic growth theory developed by Zhang. Zhang's theory is an integration of Walrasian general equilibrium theory and neoclassical growth theory with Zhang's utility function and concept of disposable income (Zhang, 2012, 2013). Walrasian general equilibrium theory was proposed by Walras and then generalized by many others (e.g., Walras, 1874; Arrow and Debreu, 1954; Debreu, 1959; Arrow and Hahn, 1971; and Mas-Colell et al., 1995). With regard to contemporary dynamic theory, the general equilibrium theory fails to properly analyze dynamics of stock variables, such as physical capital and human capital, with heterogeneous households. (e.g., Morishima, 1964, 1977; Jensen and Larsen, 2005; Montesano, 2008; Impicciatore et al., 2012). On the other hand, neoclassical growth theory is mainly concerned with dynamics of stock variables. Nevertheless, different from general equilibrium theory, neoclassical growth theory is weak at dealing with distribution issues among heterogeneous households (e.g., Solow, 1956; Burmeister and Dobell, 1970; and Barro and Sala-i-Martin, 1995). Zhang (2012, 2013) has recently made efforts in building a general economic theory by integrating the economic mechanisms of Walrasian general equilibrium theory and neoclassical growth theory with applying Zhang's utility and concept of disposable income. This study applies Zhang's theoretical framework to study dynamic interdependence between envy, wealth and income distribution between heterogeneous groups (Zhang, 2012, 2013). The paper is organized as follows. In Section 2, we build the heterogeneous-household growth model with endogenous wealth and income distribution and with destructive activities of envy. In Section 3, we study dynamic 
properties of the envy-influenced economy and simulates dynamics of a three-group economy. In Section 4, we carry comparative dynamic analysis to show effects of changes in some parameters on transitory progresses and economic equilibrium. In Section 5, we conclude the study.

\section{The Basic Model}

The model developed in this section is built on Zhang (2013). Following the Uzawa twosector model (Uzawa, 1961; Burmeister and Dobell 1970), we assume that the economy composes of capital goods and consumer goods sectors. The population is classified into multiple groups. Group j's fixed population is denoted by $\bar{N}_{j}(j=1, \ldots, J)$. We call a representative household from group $\mathrm{j}$ as household $\mathrm{j}$ Households own assets of the economy. Saving is conducted only by households. Households use up their disposable income for consuming and saving. All markets are perfectly competitive. We apply $T_{j}(t)$ to symbolize the work time of household $\mathrm{j}$. We measure prices in terms of capital goods. We choose the price of the commodity to be unity. The wage rate of worker $\mathrm{j}$ is denoted by $w_{j}(t)$. The rate of interest and the price of consumer goods are denoted by $r(t)$ and $p(t)$, respectively. The total capital stock $K(t)$ is employed by the two sectors and is used for destructive activities. Let subscript index, i and s symbolize capital goods sector and consumer goods sector, respectively. We apply $N_{m}(t)$ and $K_{m}(t)$ to represent the labor force and capital stocks employed by sector $\mathrm{m}$. Variables $F_{m}(t)$ represent output level of sector $\mathrm{m}$. We have the total population $\bar{N}$ and total qualified labor supply $\mathrm{N}(\mathrm{t})$ as follows:

$$
\bar{N}=\sum_{j=1}^{J} \bar{N}_{j}, N(t)=\sum_{j=1}^{J} h_{j} T_{j}(t) \bar{N}_{j}
$$

in which $h_{j}$ is the human capital of group $\mathrm{j}$. The assumption of labor force being fully employed implies:

$$
N_{i}(t)+N_{s}(t)=N(t)
$$

The capital goods sector

We specify the production function of the capital goods sector as follows:

$$
F_{i}(t)=A_{i} K_{i}^{\alpha_{i}}(t) N_{i}^{\beta_{i}}(t), \alpha_{i}, \beta_{i}>0, \alpha_{i}+\beta_{i}=1
$$

where $A_{i}, \alpha_{i}$, and $\beta_{i}$ are the total factor productivity, and the output elasticities of capital and labor, respectively. Let $\left(0<\delta_{k}<1\right)$ symbolize the constant depreciation rate of capital. We have the following marginal conditions for the sector:

$$
r(t)+\delta_{k}=\frac{\alpha_{i} F_{i}(t)}{K_{i}(t)}, w(t)=\frac{\beta_{i} F_{i}(t)}{N_{i}(t)}
$$

in which $w(t)$ implies the wage rate of labor. We have the wage rate for group $\mathrm{j}$ as follows:

$$
w_{j}(t)=h_{j} w(t) .
$$

The per household's wage income $W_{j}(t)$ is

$$
W_{j}(t)=h_{j} T_{j}(t) w(t)
$$

The consumer goods sector

We specify the production function of the sector as:

$$
F_{s}(t)=A_{s} K_{s}^{\alpha_{s}}(t) N_{s}^{\beta_{s}}(t), \alpha_{s}+\beta_{s}=1, \alpha_{s}, \beta_{s}>0,
$$

in which $A_{i}, \alpha_{i}$, and $\beta_{i}$ are the total factor productivity, and the output elasticities of capital and labor, respectively. We have the marginal conditions as follows:

$$
r(t)+\delta_{k}=\frac{\alpha_{s} p(t) F_{s}(t)}{K_{s}(t)}, w(t)=\frac{\beta_{s} p(t) F_{s}(t)}{N_{s}(t)}
$$


510 REMEF (The Mexican Journal of Economics and Finance)

Envy and Inequality in Income and Wealth in a Dynamic General Equilibrium Theory

\section{Zhang's Current income and disposable income}

We apply the approach to modelling household behavior proposed by Zhang $(1993,2005)$. We apply $\bar{k}_{j}(t)$ to symbolize the value of wealth owned by household $\mathrm{j}$. Let $\bar{K}_{j}(t)$ stand for the total value of wealth held by group j. According to the definitions, $\bar{k}_{j}(t)=\bar{K}_{j}(t) / \bar{N}_{j}$ holds. Household j's current income composes of the wage income and the interest payment as follows:

$$
y_{j}(t)=r(t) \bar{k}_{j}(t)+W_{j}(t)
$$

Different from the traditional concept of disposable income (which is the current income in Zhang's approach), we calculate household j's disposable income as the sum of the current income and the value of wealth:

$$
\hat{y}_{j}(t)=y_{j}(t)+\bar{k}_{j}(t)
$$

\section{Description of envy and its impact}

With regards to envy and its impact, we base our approach on the model with envy in discrete time by Gershman (2014). In Gershman's approach, the population over time is a sequence of non-overlapping generations, each generation living for one period. Each agent has a unit of time. Let $\mathrm{K}$ stand for the total endowment of the economy, which is assumed to be constant over time. The population is classified into the rich and poor. The wealth is distributed as follows: $K_{p}=\lambda K$ and $K_{r}=(1-\lambda) K$, where $\lambda$ is the given distribution parameter. Each agent allocates the available time between producing and disruption of the other agent's process. The destructive activity is due to envy. If agent i allocates a fraction $d_{i t}$ of his time to disrupt the productivity of agent $\mathrm{j}$, the latter retains only a fraction $p_{j t}$ of his final output

$$
p_{j t}=\frac{1}{1+\tau d_{i t}}, i \neq j
$$

where $\tau$ is a parameter measuring the effectiveness of destructive technology. The utility function is specified as follows

$$
U_{i t}=\frac{\left(C_{i t}-\theta C_{j t}\right)^{1-\sigma}}{1-\sigma}-L_{i t}
$$

where $L_{i t}$ is work time and $\theta$ and $\sigma$ are positive and less than one parameters.

Inspirited by Gershman's approach and some other models on envy, we assume that destructive technology $f_{j q}(t)$ is

$$
f_{j q}(t)=A_{j q} k_{j q}^{\alpha_{j q}}(t) T_{j q}^{\beta_{j q}}(t), j \neq q, j, q=1, \ldots, J, \alpha_{j q}, \beta_{j q}>0, \alpha_{j q}+\beta_{j q}=1
$$

where $A_{j q}$ are parameters, $T_{j q}(t)$ and $k_{j q}(t)$ are the time and the capital stock that household $\mathrm{j}$ uses to destroy wealth of household q. It is assumed that household q loses its wealth due to group j's envy in the following way:

$$
\bar{f}_{q j}(t)=\theta_{j q} f_{j q}(t) \bar{k}_{q}(t), j, q=1, \ldots, J
$$

where $\theta_{j q} \equiv \bar{N}_{j} / \bar{N}_{q}$. This implies that per household loss is proportional to the per household wealth and the disruption that the representative household receives. From the definitions we should require

$$
\theta_{j q} f_{j q}(t) \leq 1, j \neq q, j, q=1, \ldots, J
$$

This implies that one should not lose what one owns. According to (10), group j's per household total loss due to all the destructive activities of the society is

$$
\bar{f}_{j}(t)=\sum_{m \neq j}^{J} \bar{f}_{j m}(t), j=1, \ldots, J
$$


We assume a simplified form of possible disruption as envy can be conducted through different channels on various people. For instance, there may be "joint productions" in destructive activities in the sense that one action may have destructive effects on different groups. For simplicity, we are only concerned with destructive sides of envy. Envy and its destructive impact are related to various variables such as family background, individual human capital, education, social environment, education, networks and relations with celebrities, relative richness in group (Gershman, 2013). By the way our approach can also deal with other variables such as sympathy or hatred. If a rich group has strong sympathy towards the poor, it is possible for the rich to make efforts to help the poor. In our approach, this can be dealt with by taking $A_{j q}$ as a negative number and making proper adjustments in the rest of the model. Taxation by the government may be technically considered as a special form of sympathy. Hatred may be modelled similarly as envy.

\section{Budget constraints with destructive activities}

The disposable income is used for saving and consumption. The representative household from group $\mathrm{j}$ would distribute the total available budget between savings $s_{j}(t)$, consumer goods $c_{j}(t)$, and capital for destructive actions. The household also loses wealth due to destructive activities of the society. The budget constraint means

$$
p(t) c_{j}(t)+\left(r(t)+\delta_{k}\right) \sum_{m \neq j}^{J} k_{j m}(t)+s_{j}(t)+\bar{f}_{j}(t)=y j t
$$

Let $T_{0 j}$ stand for the total available time that each household from group $\mathrm{j}$ has for work and destructive activities. The available time is distributed between work and destructive activities

$$
T_{j}(t)+\sum_{q \neq j}^{J} T_{j q}(t)=T_{0 j}
$$

Insert (13) in (8)

$$
\hat{y}_{j}(t)=y j t-h j w t m j J T j q t
$$

in which

$$
\bar{y}_{j}(t) \equiv(1+r(t)) \bar{k}_{j}(t)+h_{j} w(t) T_{0 j}-\bar{f}_{j}(t)
$$

Substitute (13) in (11)

$$
p(t) c_{j}(t)+\left(r(t)+\delta_{k}\right) \sum_{m \neq j}^{J} k_{j m}(t)+h_{j} w(t) \sum_{m \neq j}^{J} T_{j q}(t)+s_{j}(t)=\bar{y}_{j}(t)
$$

\section{Envy and Utility functions}

It is assumed that utility level $U_{j}(t)$ is related to variables $c_{j}(t), s_{j}(t)$ and $f_{j q}(t)$ as follows:

$$
U_{j}(t)=c_{j}^{\xi_{j 0}}(t) s_{j}^{\lambda_{j 0}}(t) \prod_{q \neq j}^{J} \bar{f}_{j q}^{\omega_{j q 0}}(t), \xi_{j 0}, \lambda_{j 0}>0, \omega_{j q 0} \geq 0
$$

in which $\xi_{j 0}$ represents the propensity to consume consumer goods, $\lambda_{j 0}$ the propensity to save, and $\omega_{j q 0}$ is group j's propensity to destroy group q's property. It should be noted that in the theoretical literature of economic growth and development, most of formal models is built on the Ramsey approach to household behavior. The heterogeneity between households is assumed due to differences in initial endowments of wealth rather than in preferences (e.g., Caselli and Ventura, 2000; and Turnovsky and Penalosa, 2006). This approach in the traditional approach explains, at least partly, why modern growth theories have little to say about implications of heterogeneity in households' preferences. Zhang's approach is an alternative approach to the traditional approaches, which make it possible to deal with different issues of economic growth and development with heterogeneous households. 
512 REMEF (The Mexican Journal of Economics and Finance)

Envy and Inequality in Income and Wealth in a Dynamic General Equilibrium Theory

Maximizing utility

Maximizing utility

$$
\begin{gathered}
p(t) c_{j}(t)=\xi_{j} \bar{y}_{j}(t), s_{j}(t)=\lambda_{j} \bar{y}_{j}(t),\left(r(t)+\delta_{k}\right) k_{j q}(t)=\widetilde{\alpha}_{j q} \bar{y}_{j}(t), h_{j} w(t) T_{j q}(t) \\
=\widetilde{\beta}_{j q} \bar{y}_{j}(t) \quad(16)
\end{gathered}
$$

where

$$
\xi_{j} \equiv \rho_{j} \xi_{j 0}, \lambda_{j} \equiv \rho_{j} \lambda_{j 0}, \widetilde{\alpha}_{j q} \equiv \alpha_{j q} \rho_{j} \omega_{j q 0}, \widetilde{\beta}_{j q} \equiv \beta_{j q} \rho_{j} \omega_{j q 0}, \rho_{j} \equiv \frac{1}{\xi_{j 0}+\lambda_{j 0}+\sum_{q \neq j}^{J} \omega_{j q 0}}
$$

\section{Wealth accumulation}

The change in wealth is equal to saving minus dissaving

$$
\bar{k}_{j}(t)=s_{j}(t)-\bar{k}_{j}(t)
$$

Equilibrium conditions for the two sectors

For the consumer goods sector, we have

$$
\sum_{j=1}^{J} c_{j}(t) \bar{N}_{j}=F_{s}(t)
$$

For capital goods market, output of the capital goods sector is used up for the depreciation of capital stock and the net savings. We thus have

$$
S(t)-K(t)+\delta_{k} K(t)=F_{i}(t)
$$

in which

$$
S(t) \equiv \sum_{j=1}^{J} s_{j}(t) \bar{N}_{j}, K(t)=\sum_{j=1}^{J} \bar{k}_{j}(t) \bar{N}_{j}
$$

Full employment of capital

The two sectors and destructive activities fully use up the total capital stock $K(t)$

$$
K_{i}(t)+K_{s}(t)+\sum_{j=1}^{J} K_{j}(t)=K(t)
$$

in which $K_{j}(t)$ represent the capital stocks that group $\mathrm{j}$ uses for destructive activities

$$
K_{j}=\bar{N}_{j} \sum_{q \neq j}^{J} k_{j q}(t)
$$

We built the model. The model is structurally general in the sense that we can consider some well-known models, such as the Solow one-sector growth model (Solow, 1956), the Uzawa two-sector growth model (Uzawa, 1961), and Walrasian general equilibrium theory, in economic growth theory as its special cases. The new aspect of this study is the introduction of envy into neoclassical growth theory with heterogeneous households.

\section{Dynamic properties of the envy-influenced growth model}

As the dynamic system contains many variables and these variables are nonlinearly interrelated, it is difficult to obtain analytically dynamic properties of the model. Nevertheless, we now show that we can follow the movement of the system by simulation. Before stating the main result of this section, we define the following variables:

$$
\begin{gathered}
z(t) \equiv \frac{r(t)+\delta_{k}}{w(t)}, \\
\left\{\bar{y}_{j}(t)\right\} \equiv\left(\bar{y}_{2}(t), \cdots, \bar{y}_{J}(t)\right)
\end{gathered}
$$

We also use $\Omega_{j}(t)$ to stand for unique functions of $z(t)$ and $\left\{\bar{y}_{j}(t)\right\}$ and these functions are defined in the Appendix. For simplicity of analysis, it is assumed that the richest group (group 1 as specified in simulation) does not to envy any other group and hence conducts no destructive activity. That is $A_{1 q}=\omega_{01 q}=0$, for any q. Nevertheless, the rich group may suffer losses from other groups' destructive activities. 


\section{Lemma}

The following $\mathrm{J}$ differential equations determine motion of the economic system:

$$
\begin{gathered}
\dot{z}(t)=\Omega_{1}\left(z(t),\left\{\bar{y}_{j}(t)\right\}\right), \\
j(t)=\Omega_{j}\left(z(t),\left\{\bar{y}_{j}(t)\right\}\right), j=2, \ldots, J
\end{gathered}
$$

The other variables are uniquely related to $z(t)$ and $\bar{y}_{j}(t)$ as follows: $r(t)$ and $w_{j}(t)$ with $(A 2)(t)$ with $(A 3) \rightarrow \bar{y}_{1}(t)$ from $(A 19) \rightarrow \bar{k}_{j}(t)$ from $(A 12) \rightarrow K(t)=\sum_{j=1}^{J} \bar{k}_{j}(t) \bar{N}_{j} \rightarrow$ $c_{j}(t), s_{j}(t), k_{j q}(t)$, and $T_{j q}(t)$ from $(16) \rightarrow T_{j}(t)$ with $(13)(t)$ from $(1) \rightarrow w(t)=$ $w_{1}(t) / h_{1} \rightarrow K_{j}(t)$ with $(A 5) \rightarrow N_{s}(t)$ from $(A 4) \rightarrow N_{i}(t)$ from $(A 7) \rightarrow K_{s}(t)$ and $K_{i}(t)$ with $(A 1) \rightarrow F_{i}(t) a n d F_{s}(t)$ by the definitions $\rightarrow f_{j q}(t)$ from $(A 9) \rightarrow \bar{f}_{j q}(t)$ by $(A 10) \rightarrow \bar{f}_{j}(t)$ by $(\mathrm{A} 12)$.

From the computational procedure in the Lemma we determine the motion of the economic system. Simulation can be easily conducted for any number of households as we already provide the computational procedure. We now consider a three-group economy. The parameter values of the envy-influenced growth model are specified as follows: $A_{i}=1,3, A_{s}=1, \alpha_{i}=0,34, \alpha_{s}=0,3, T_{0}=8, \delta_{k}=0,05$,

$$
\begin{gathered}
\left(\begin{array}{l}
\bar{N}_{1} \\
\bar{N}_{2} \\
\bar{N}_{3}
\end{array}\right)=\left(\begin{array}{c}
5 \\
50 \\
100
\end{array}\right),\left(\begin{array}{l}
h_{1} \\
h_{2} \\
h_{3}
\end{array}\right)=\left(\begin{array}{l}
6 \\
2 \\
1
\end{array}\right),\left(\begin{array}{l}
\lambda_{10} \\
\lambda_{20} \\
\lambda_{30}
\end{array}\right)=\left(\begin{array}{c}
0,9 \\
0,8 \\
0,73
\end{array}\right),\left(\begin{array}{l}
\xi_{10} \\
\xi_{20} \\
\xi_{30}
\end{array}\right)=\left(\begin{array}{c}
0,1 \\
0,17 \\
0,22
\end{array}\right),\left(\begin{array}{l}
\omega_{210} \\
\omega_{230}
\end{array}\right)= \\
\left(\begin{array}{c}
0,02 \\
0,01
\end{array}\right),\left(\begin{array}{l}
\omega_{310} \\
\omega_{320}
\end{array}\right)=\left(\begin{array}{l}
0,03 \\
0,02
\end{array}\right),\left(\begin{array}{l}
A_{21} \\
A_{23}
\end{array}\right)=\left(\begin{array}{l}
A_{31} \\
A_{32}
\end{array}\right)=\left(\begin{array}{c}
0,1 \\
0,1
\end{array}\right),\left(\begin{array}{l}
\alpha_{21} \\
\alpha_{23}
\end{array}\right)=\left(\begin{array}{l}
\alpha_{31} \\
\alpha_{32}
\end{array}\right)=\left(\begin{array}{l}
0,3 \\
0,3
\end{array}\right)
\end{gathered}
$$

We assume the population of group 3 to be largest and the population of group 2 the next. We specify he capital goods and consumer goods sector's total productivities 1.3 and 1 , respectively. The values of the parameters $\alpha_{j}$ are approximately 0.3 . The depreciation rate of physical capital is specified at 0.05 . The initial conditions are

$$
z(0)=0,095, \bar{k}_{2}(0)=97, \bar{k}_{3}(0)=55
$$

The motion of the variables is plotted in Figure 1. In Figure 1, the national income is

$$
Y(t)=F_{i}(t)+p(t) F_{s}(t)
$$

The national output, total labor supply and national wealth fall from the initial conditions over time. The output level of the capital goods sector is reduced, while the output level of the consumer goods sector is enhanced. The rate of interest rises as the wage rates fall. The price of consumer goods is reduced. Group 1's per capita wealth, per capita consumption, and wealth are reduced by the other two groups' destructive activities against group 1. Nevertheless, as group 1 has less wealth, the other two groups' destructive activities become less effective. Group 2's per capita wealth and consumption levels almost not changed. Group 3's per capita wealth and consumption levels rise. The envy reduces the wealth gaps between group 1 and other two groups. The jealous groups work less and spend more time on destructive activities. 
514 REMEF (The Mexican Journal of Economics and Finance)

Envy and Inequality in Income and Wealth in a Dynamic General Equilibrium Theory

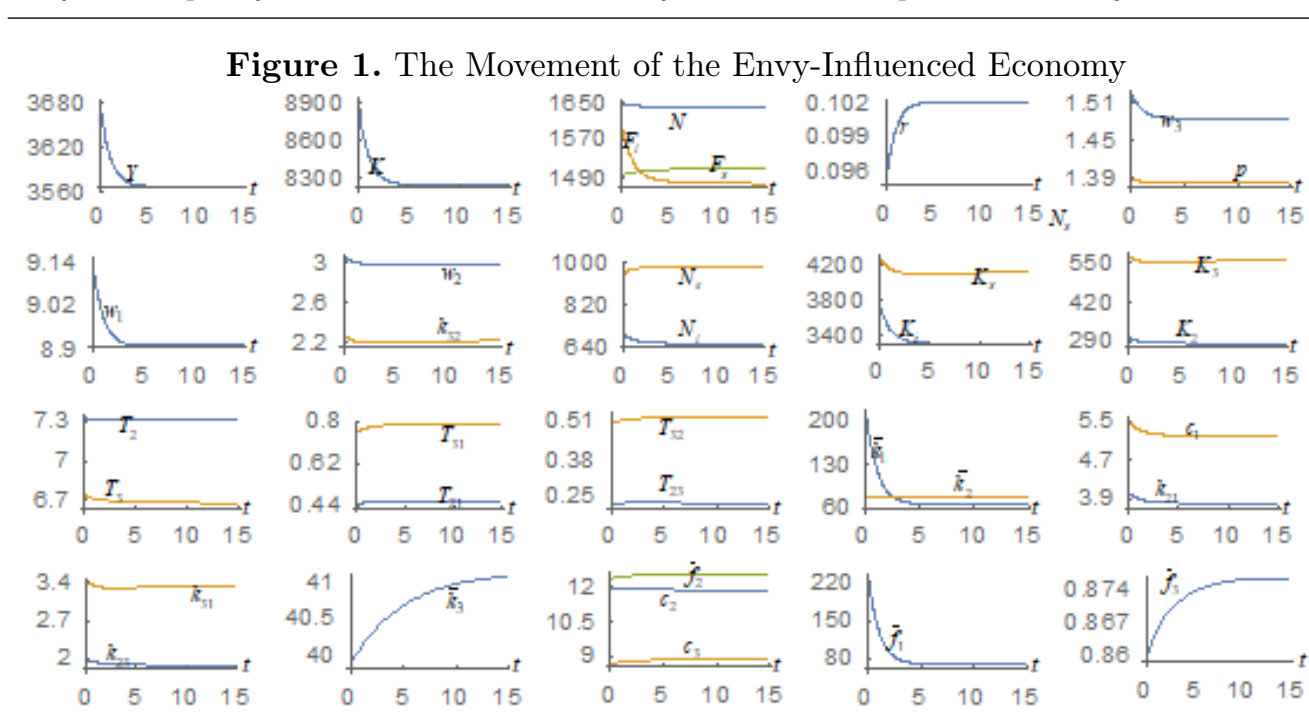

Figure 1 shows the existence of equilibrium point. We find the equilibrium values as follows:

$$
\begin{gathered}
Y=3449,2, K=8063,1, N=1597,9, r=0,105, p=1,38, w_{1}=8,84, w_{2}=2,95, \\
w_{3}=1,47, F_{i}=1524,9, F_{s}=1394,1, N_{i}=683,3, N_{s}=914,6, K_{i}=3348,2 \\
K_{s}=3728,1, K_{2}=481,4, K_{3}=505,4, T_{2}=6,82, T_{21}=0,71, T_{23}=0,47, T_{3}=6,76, \\
\bar{k}_{1}=55,7, \bar{k}_{2}=79,5, \bar{k}_{3}=38,1, c_{1}=4,48, c_{2}=10,8, c_{3}=8,3, k_{21}=5,78, k_{23}=3,85, \\
T_{31}=0,74, T_{32}=0,50, k_{31}=3,03, k_{32}=2,03, f_{1}=70,3, f_{2}=12,02, f_{3}=1,69 .
\end{gathered}
$$

We solve the three eigenvalues as follows: $\{-0,96,-0,26,-0,19\}$.

The three real and negative eigenvalues. The equilibrium point is locally stable. This guarantees the validity of comparative dynamic analysis.

\section{Comparative Dynamic Analysis}

The previous section plotted the movement of the envy-influenced economy under (23). We now apply the computational procedure from the Lemma to make comparative dynamic analysis. This enables us to know effects of anon transitory processes and equilibrium. We use a variable xjt to represent the change rate of the variable, $x_{j}(t)$, in percentage caused by a change in the parameter.

\subsection{The middle class enhance its destructive efficiency against the rich}

We now consider the case that the middle strengthens its destructiveness against the rich due to envy as follows: $A_{21}: 0,1 \Rightarrow 0,012$. Figure 2 plots the simulation result. As the middle class more effectively destroys the rich's wealth, the national wealth, income and labor supply are all decreased. The rate of interest is increased. The wage rates fall. The capital goods sector produces more output initially but finally reduces output level. The sector employs more labor and capital inputs initially but less in the long term. The consumer goods sector produces less output, and employ less labor and capital inputs. The rich lose more by the middle class's destructive activities but less by the poor. The rich have less wealth and consume less consumer goods. The rich lose more wealth initially and loses less then. The middle class and the poor lose less wealth due to their destructive 
activities. Both the middle class and poor work less and use more times on destroying the others' wealth. The middle class consume more consumer goods and own less wealth. The poor finally consume more consumer goods and have more wealth.

Figure 2. The Middle Class Enhance the Destructive Efficiency against the Rich
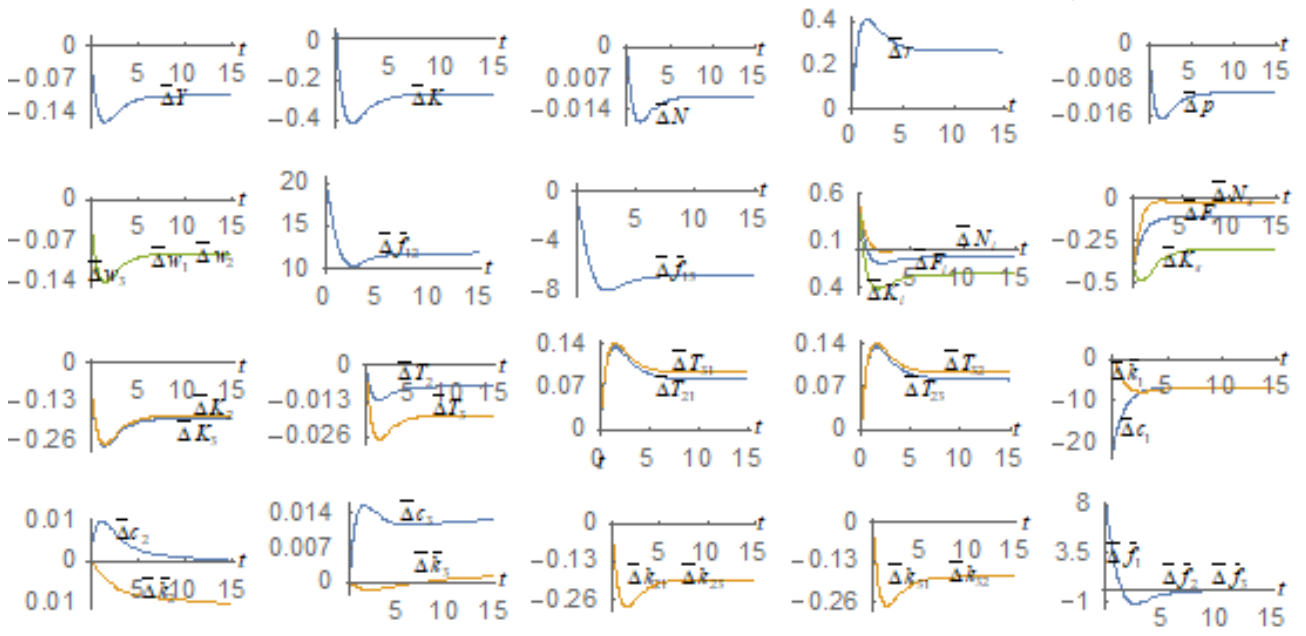

\subsection{The middle class enhance the propensity to destroy the rich's wealth}

We now study the impact of a change in the middle class's propensity to destroy the rich's wealth as follows: $\omega_{210}: 0,02 \Rightarrow 0,022$. The simulation result is illustrated in Figure 3. Similar to the previous case when the middle class improves its destructiveness efficiency, the national wealth, income and labor supply are reduced. The rate of interest rises and the wage rates fall. Different from the previous case, both the capital goods and consumer goods sectors' output levels and labor and capital inputs fall over time. The rich lose more due to the middle class's destructive activities but less due to the poor. The rich have less wealth and consume less consumer goods. The rich lose more wealth due to the destructive activities initially and there is almost no change in losses in the long term. Both the middle class and the poor lose less due to the destructive activities. Both the middle class and poor work less and use more times in destroying the others' wealth. The middle class consume less consumer goods and have less wealth. The middle class spend more time on destroying the rich's wealth and less time on the poor's. The poor spend more time on destroying the middle class and do not change the time on the rich. The poor consume more consumer goods and have more wealth in the long term. We see that by strengthening its envy against the rich, in terms of consumption and wealth the middle class and the rich suffer and the poor benefit. This also implies that the inequality gaps between the rich and the poor are reduced. It should be noted that in modelling an economy with overlapping generations and heterogeneous agents, Alvarez-Cuadrado and Long (2012: 949) find out: "envy reduces the steady-state capital stock and increases the degree of inequality in consumption, capital ownership, and bequests". Our simulation shows that a strengthened envy from a group reduces the national wealth, reduces some groups' wealth and increases others' wealth. 
516 REMEF (The Mexican Journal of Economics and Finance)

Envy and Inequality in Income and Wealth in a Dynamic General Equilibrium Theory

Figure 3. The Middle Class Enhance the Propensity to Destroy the Rich's Wealth
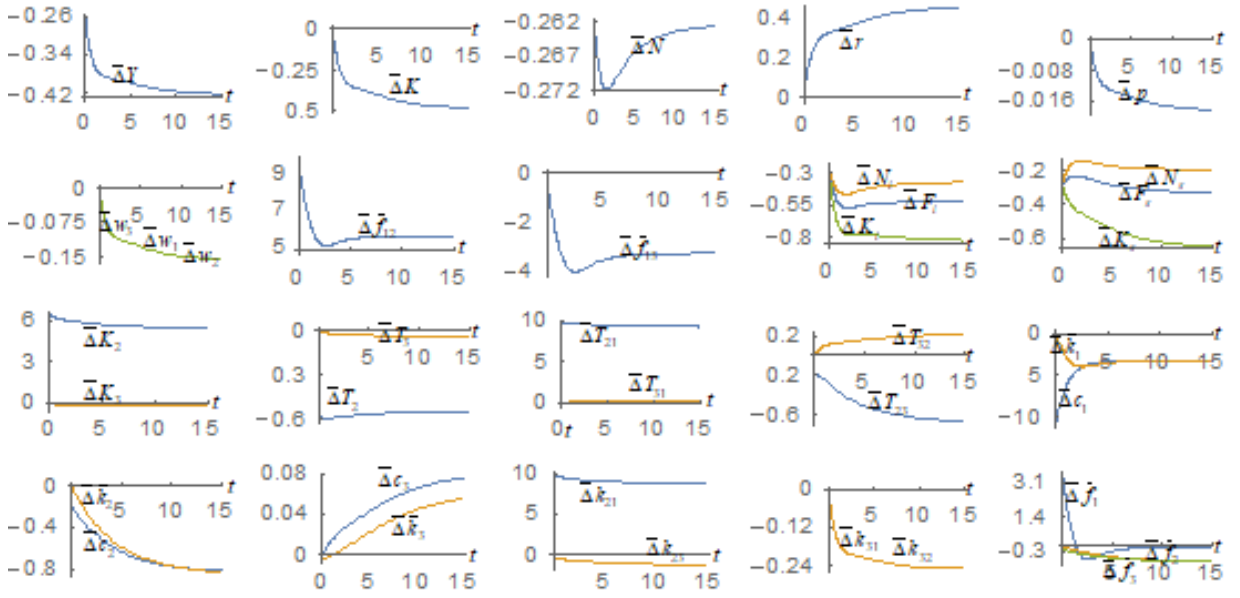

\subsection{The middle class's human capital is improved}

We now study the case that the middle class's human capital is changed as follows: $h_{2}: 2 \Rightarrow 2,2$. We summarize the simulation result Figure 4 . The national wealth, income and labor supply are increased. The rate of interest is increased. We have higher wage rate of the middle class, but almost same wage rates for the other two classes. Both the capital goods and consumer goods sectors' output levels and labor and capital inputs are enhanced over time. The rich's loss in wealth due to the middle class' and the poor's destructive activities rise initially and finally fall slightly. The rich's consumption is increased initially and reduced in the long term. The rich's wealth falls. The middle class spend less time and use more capital on destructive activities both against the rich and the poor. The middle class' wealth loss is increased as the class becomes wealthy. In the long term the wealth losses of the rich and the poor are slightly affected by the middle class's human capital improvement. The middle class attracts more destructive activities against the class as it becomes wealthy. In the long term the middle class benefits in terms of consumption level and wealth and the poor and rich lose.

Figure 4. The Middle Class's Human Capital Is Improved
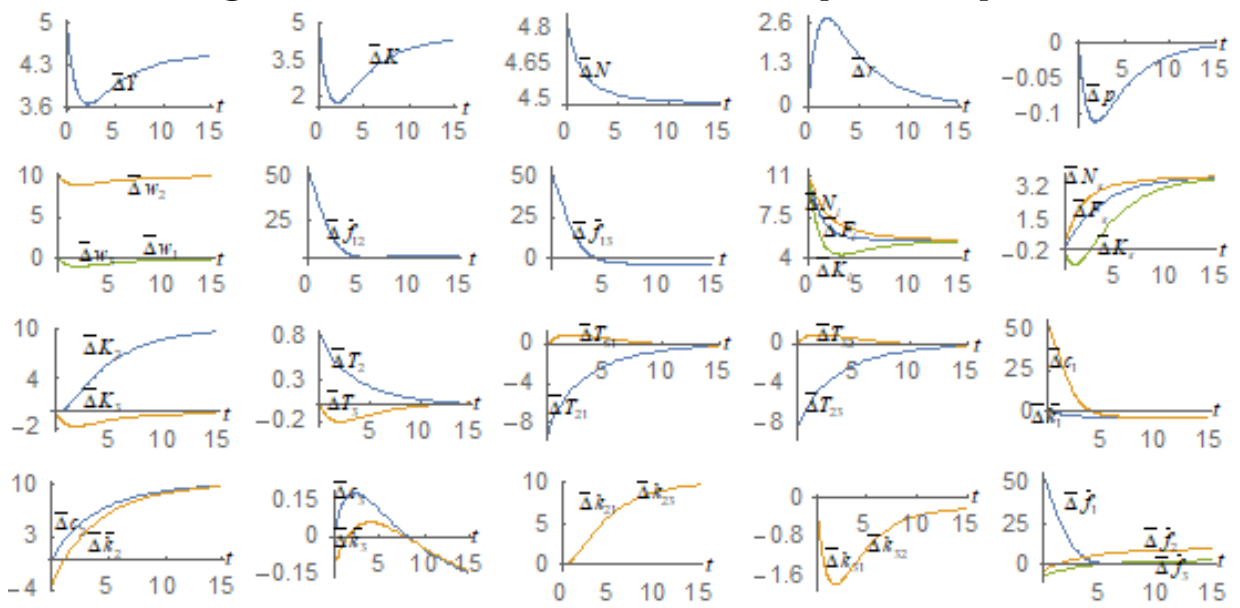


\subsection{The middle class increase the propensity to save}

We study the case that the middle class augment the propensity to save as follows: $\lambda_{20}: 0,8 \Rightarrow 0,9$. The simulation result is summarized in Figure 5 . The national wealth, income and labor supply are increased. The wage rates are enhanced. The rate of interest is reduced. The price of consumer goods is enhanced. The capital goods sector's output levels and labor and capital inputs are enhanced. The consumer goods sector's output levels and labor input are reduced. The consumer goods sector's capital input is reduced initially and finally increased. The rich lose less due to the middle class and lose more due to the poor's destructive activities. The middle and poor spend more time on working and less time on destructive activities. The rich consume more and own more. The middle class own more and consume less. The poor consume more. The poor owns less initially and finally more. The rich and middle class lose more due to the destructive activities and the poor lose less.

Figure 5. The Middle Class Increase Propensity to Save
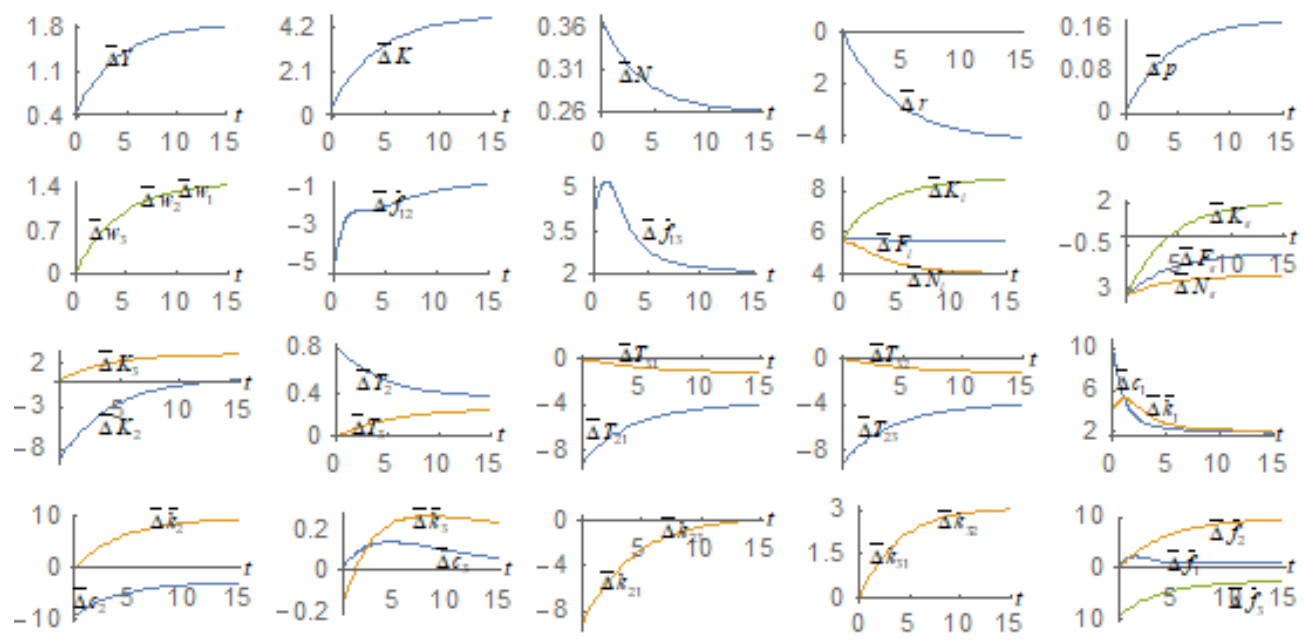

\subsection{The rich population is increased}

We now deal with the case that the rich population is increased as follows: $\bar{N}_{1}: 5 \Rightarrow$ 6 Figure 6 shows the simulation result. The population change augments the national wealth, income and labor supply. The wage rates fall. The rate of interest is increased. The capital goods and consumer goods sectors' output levels and labor and capital inputs are enhanced over time. The representative household of the rich loses less due to each of the two other classes' destructive activities and loses more in the long term. The rich and poor households' consumption and wealth are increased. The middle class and poor spend less hours on working and more hours on destructive activities. 
Figure 6. The Rich Population Is Increased
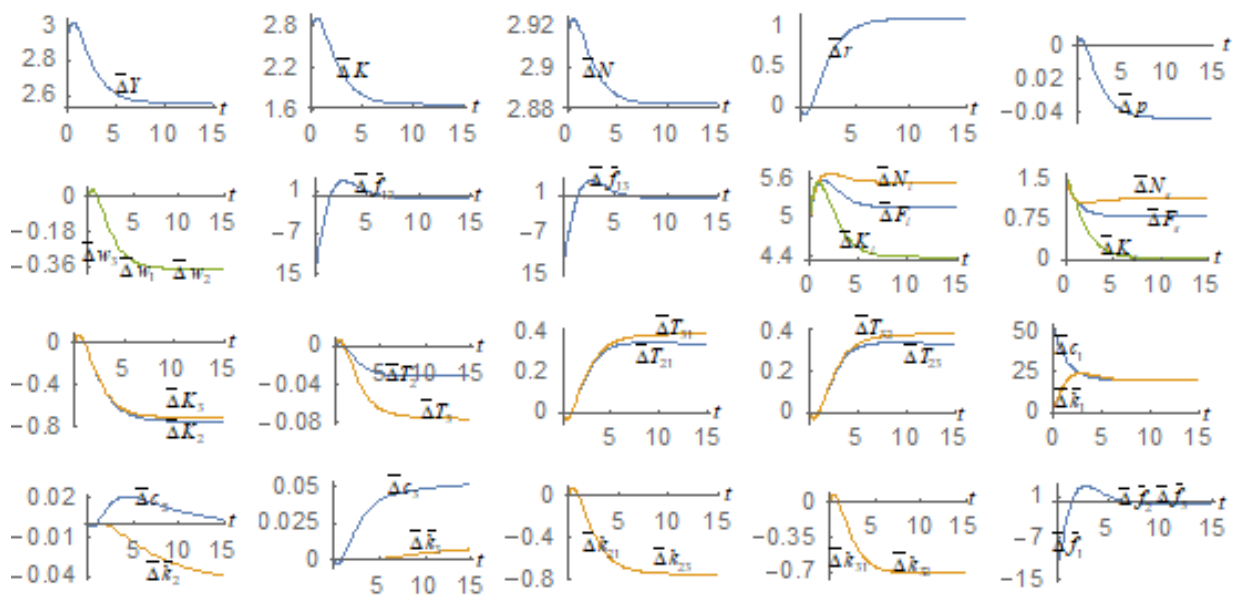

\subsection{The capital goods sector's total factor productivity is enhan- ced}

We now study the case that the capital goods sector's total factor productivity is changed follows: $A_{i}: 1,3 \Rightarrow 1,4$. Figure7 shows the simulation result. The national output and national wealth are augmented. The price of consumer goods is enhanced. The rate of interest. The wage rates rise. The capital goods sector's total output and two factor inputs are increased. The total labor supply rises. The consumer goods sector's labor is reduced. The consumer goods sector's output and capital input are reduced initially and finally increased. The rich lose more due to each of the other two classes' attacks. All the three groups lose more wealth because of the destructive activities in the society. The middle class and the poor spend more hours on working and less hours on destructive activities. Everyone finally benefits from the technological improvement in terms of consumption and wealth.

Figure 7. The Capital Goods Sector's Total Factor Productivity is Enhanced
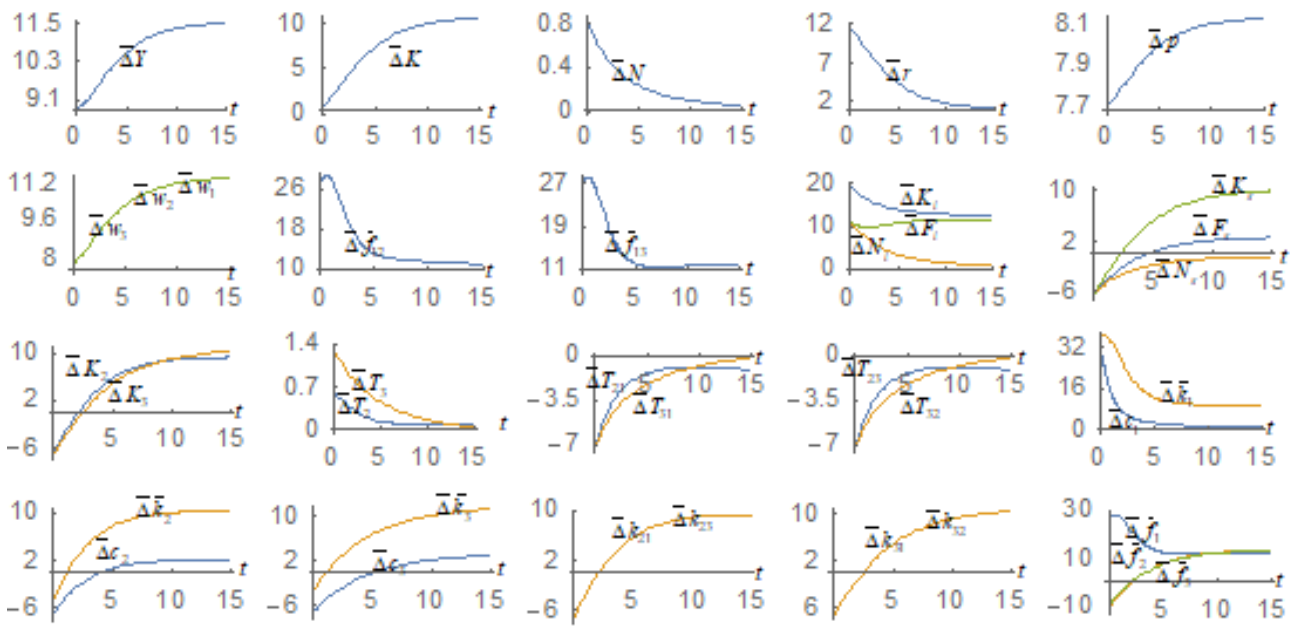


\section{Concluding Remarks}

This study analyzed dynamic interactions between envy, economic growth and income and wealth distribution. We built a heterogeneous-household growth model with endogenous economic structure and envy. The unique contribution of this study is to examine the role of destructive side of envy on economic structural change and wealth and income distribution. The basic idea about modelling envy was inspirited by the literature of economics of envy. The motion of the envy-influenced heterogeneous-household is described by differential equations. We simulated the motion of a three-group economy. These groups are called the rich, the middle class, and the poor, respectively. We showed the existence of a locally stable equilibrium point. We conducted comparative dynamic analysis with regard to the middle class's destructive efficiency against the rich, in the middle class's human capital, the middle class's propensity to save, the rich population, and the capital goods sector's total factor productivity. We examined how changes in these parameters shift transitory processes and long-term equilibrium structure. For instance, our simulation showed that as the middle class increase the propensity to destroy the rich's wealth, the effects on the economy are summarized as follows: (i) the national wealth, income and labor supply being reduced; (ii) the rate of interest is increased and the wage rates are lowered; (iii) both the capital goods and consumer goods sectors' output levels and labor and capital inputs falling over time; (iv) the rich losing more due to the middle class's destructive activities but less due to the poor's destructive activities, the rich having less wealth and consume less consumer goods; and there being almost no change in losses in the long term; (v) both the middle class and the poor losing less due to the destructive activities, both the middle class and poor working less and using more times in destroying the others' wealth; (vi) the middle class consuming less consumer goods and having less wealth; the middle class spend more time on destroying the rich's wealth and less time on the poor's; (vii) the poor spending more time on destroying the middle class and do not change the time on the rich, and the poor consuming more consumer goods and having more wealth in the long term; and (viii) in terms of consumption and wealth, the middle class and the rich suffer and the poor benefit. As our model is built in a very general analytical framework, we may generalize the model in various directions. For instance, we may take account of constructive side of envy in our modelling framework. 


\section{Appendix: Checking the Lemma}

Equations (4) and (7) imply

$$
z \equiv \frac{r+\delta_{k}}{w}=\frac{N_{i}}{\bar{\beta}_{i} K_{i}}=\frac{N_{s}}{\bar{\beta}_{s} K_{s}}
$$

where $\bar{\beta}_{j} \equiv \beta_{m} / \alpha_{m}$. Insert (A1) in (4)

$$
r=\alpha_{r} z^{\beta_{i}}-\delta_{k}, w_{j}=\alpha_{w} h_{j} z^{-\alpha_{i}},
$$

where

$$
\alpha_{r}=\alpha_{i} A_{i} \bar{\beta}_{i}^{\beta_{i}}, \alpha_{w}=\beta_{i} A_{i} \bar{\beta}_{i}^{-\alpha_{i}}
$$

From (6) and (7), we get

$$
p=\frac{\bar{\beta}_{s}^{\alpha_{s}} z^{\alpha_{s}} w}{\beta_{s} A_{s}}
$$

Insert $p c_{j}=\xi_{j} \bar{y}_{j}$ in (18)

$$
\beta_{s} \sum_{j=1}^{J} \xi_{j} \bar{N}_{j} \bar{y}_{j}=w N_{s}
$$

where we apply $p F_{s}=w N_{s} / \beta_{s}$. From (21) and $\left(r+\delta_{k}\right) k_{j q}=\widetilde{\alpha}_{j q} \bar{y}_{j}$ in (16), we get

$$
K_{1}=0, K_{j}=\frac{\widetilde{\alpha}_{j} \bar{y}_{j}}{r+\delta_{k}}, j \neq 1
$$

where

$$
\widetilde{\alpha}_{1} \equiv 0, \widetilde{\alpha}_{j} \equiv \bar{N}_{j} \sum_{q \neq j}^{J} \widetilde{\alpha}_{j q}, j=2, \ldots, J
$$

Insert (A1) and (A5) in (20)

$$
\frac{N_{i}}{\bar{\beta}_{i}}+\frac{N_{s}}{\bar{\beta}_{s}}+\frac{1}{w} \sum_{j=2}^{J} \widetilde{\alpha}_{j} \bar{y}_{j}=z K
$$

Insert (A4) in (A6)

$$
\frac{w N_{i}}{\beta_{i}}+\sum_{j=1}^{J} \widetilde{\beta}_{j} \bar{y}_{j}=z w K
$$

where

$$
\widetilde{\beta}_{j} \equiv \frac{\beta_{s} \xi_{j} \bar{N}_{j}}{\bar{\beta}_{s}}+\widetilde{\alpha}_{j}
$$

With (11) and the definitions of yj, it is straightforward to get

$$
\bar{y}_{j}=(1+r) \bar{k}_{j}+w_{j} T_{0 j}-\sum_{q \neq m, m \neq 1}^{J} \bar{f}_{m q}
$$

With (9) and (10) we get

$$
\bar{f}_{q 1}=0, \bar{f}_{q j}=\theta_{j q} A_{j q} k_{j q}^{\alpha_{j q}} T_{j q}^{\beta_{j q}} k_{q}, j \neq q, j, q=1, \ldots, J
$$

Insert (16) in (A9)

$$
\bar{f}_{q j}=\widetilde{\theta}_{q j} \bar{y}_{j} \bar{k}_{q}, j \neq 1
$$

where

$$
\widetilde{\theta}_{q j}=\theta_{j q} A_{j q}\left(\frac{\widetilde{\alpha}_{j q}}{r+\delta_{k}}\right)^{\alpha_{j q}}\left(\frac{\widetilde{\beta}_{j q}}{h_{j} w}\right)^{\beta_{j q}}
$$


Insert (A8) in (A10)

$$
\bar{y}_{j}+\bar{k}_{j} \sum_{q \neq j, 1}^{J} \widetilde{\theta}_{j q} \bar{y}_{q}=(1+r) \bar{k}_{j}+w_{j} T_{0 j}, j=1, \ldots, J
$$

If we consider $\bar{k}_{j}$ as the variables in (A11), then the linear equations system have $\mathrm{J}$ variables and $\mathrm{J}$ equations. We solve these linear equations as follows:

$$
\bar{k}_{j}=\Lambda_{j}\left(z,\left(\bar{y}_{q}\right)\right) \equiv \frac{\bar{y}_{j}-h_{j} w T_{0 j}}{1+r-\sum_{q \neq j, 1}^{J} \tilde{\theta}_{j q} \bar{y}_{q}}, j=1, \ldots, J
$$

From (13) and (16) we have

$$
T_{j}=T_{0 j}-R_{j} \bar{y}_{j}
$$

where

$$
R_{j}(z) \equiv \frac{1}{w_{j}} \sum_{q \neq j}^{J} \widetilde{\beta}_{j q}
$$

Insert (A13) in (1)

$$
N=H-\sum_{j=1}^{J} h_{j} R_{j} \bar{N}_{j} \bar{y}_{j}
$$

where

$$
H \equiv \sum_{j=1}^{J} h_{j} T_{0 j} \bar{N}_{j}
$$

By (2) and (A14) we have

$$
N_{i}+N_{s}=H-\sum_{j=1}^{J} h_{j} R_{j} \bar{N}_{j} \bar{y}_{j}
$$

Substitute (A4) and (A7) into (A15)

$$
\bar{\beta}_{i} z K+\sum_{j=1}^{J} \widetilde{R}_{j} \bar{y}_{j}=H
$$

where

$$
\widetilde{R}_{j} \equiv \frac{\beta_{s} \xi_{j} \bar{N}_{j}}{w}+h_{j} R_{j} \bar{N}_{j}-\frac{\bar{\beta}_{i} \widetilde{\beta}_{j}}{w}
$$

Insert $K=\sum_{j=1}^{J} \bar{k}_{j} \bar{N}_{j}$ in (A16)

$$
\bar{\beta}_{i} z \sum_{j=1}^{J} \bar{k}_{j} \bar{N}_{j}+\sum_{j=1}^{J} \widetilde{R}_{j} \bar{y}_{j}=H
$$

Insert (A12) in (A17)

$$
\frac{\left(\bar{y}_{1}-h_{1} w T_{01}\right) \bar{\beta}_{i} z \bar{N}_{1}}{1+r-\sum_{2}^{J} \widetilde{\theta}_{1 q} \bar{y}_{q}}+\widetilde{R}_{1} \bar{y}_{1}=\Lambda_{0}
$$

where

$$
\Lambda_{0}\left(z,\left\{\bar{y}_{q}\right\}\right) \equiv H-\sum_{j=2}^{J} \widetilde{R}_{j} \bar{y}_{j}-i z j=2 J j z, \bar{y} q \bar{N} j
$$

Solve (A20) with y1 as the variable

$$
\bar{y}_{1}=\Lambda\left(z,\left\{\bar{y}_{q}\right\}\right) \equiv\left(\Lambda_{0}+\frac{\bar{\beta}_{i} h_{1} w T_{01} z \bar{N}_{1}}{1+r-\sum_{2}^{J} \widetilde{\theta}_{1 q} \bar{y}_{q}}\right)\left(\frac{\bar{\beta}_{i} z \bar{N}_{1}}{1+r-\sum_{2}^{J} \widetilde{\theta}_{1 q} \bar{y}_{q}}+\widetilde{R}_{1}\right)^{-1}
$$

We determine the variables as functions of $\mathrm{z}$ and $\left\{\bar{y}_{j}\right\}$ by the following procedure: $\mathrm{r}$ and $w_{j}$ with (A2) with (A3) $\rightarrow \bar{y}_{1}$ with (A19) $\rightarrow \bar{k}_{j}$ with (A12) $\rightarrow K=\sum_{j=1}^{J} \bar{k}_{j} \bar{N}_{j} \rightarrow c_{j}, s_{j}, k_{j q}$, and $T_{j q}$ with (16) $\rightarrow T_{j}$ with (13) $\rightarrow \mathrm{N}$ with $(1) \rightarrow w=w_{1} / h_{1} \rightarrow K_{j}$ with (A5) $\rightarrow N_{s}$ with (A4) $\rightarrow N_{i}$ with (A7) $\rightarrow K_{s}$ and $K_{i}$ with (A1) $\rightarrow F_{i}$ and $F_{s}$ with the definitions $\rightarrow f_{j q}$ from $(\mathrm{A} 9) \rightarrow \bar{f}_{j q}$ by (A10) $\rightarrow \bar{f}_{j}$ by (A12). From the procedure, (A12) and (17), the changes in wealth are given as follows: 
522 REMEF (The Mexican Journal of Economics and Finance)

Envy and Inequality in Income and Wealth in a Dynamic General Equilibrium Theory

$$
\dot{\bar{k}}_{j}=\widetilde{\Lambda}_{j}\left(z,\left\{\bar{y}_{j}\right\}\right) \equiv \lambda_{j} \bar{y}_{j}-\Lambda_{j}, j=1, \ldots, J
$$

Taking derivatives of (A12) in t, we get

$$
\dot{\bar{k}}_{j}=\frac{\partial \Lambda_{j}}{\partial z} \dot{z}+\sum_{j=2}^{J} \frac{\partial \Lambda_{j}}{\partial \bar{y}_{j}} \dot{\bar{y}}_{j}, j=1, \ldots, J
$$

From (A20) and (A21), we get

$$
\frac{\partial \Lambda_{j}}{\partial z} \dot{z}+\sum_{j=2}^{J} \frac{\partial \Lambda_{j}}{\partial \bar{y}_{j}} \dot{\bar{y}}_{j}=\widetilde{\Lambda}_{j}, j=1, \ldots, J
$$

Differential system (A22) has $\mathrm{J}$ variables, z and $\left\{\bar{y}_{j}\right\}$ and consists of $\mathrm{J}$ linear equations. It is straightforward to solve (A22)

$$
\begin{array}{r}
\dot{z}=\Omega_{1}\left(z,\left\{\bar{y}_{j}\right\}\right), \\
{ }_{j}=\Omega_{j}\left(z,\left\{\bar{y}_{j}\right\}\right), j=2, \ldots, J
\end{array}
$$

We confirmed the Lemma.

\section{References}

Arrow K.J. and Debreu, G. (1954) Existence of an Equilibrium for a Competitive Economy. Econometrica $22,265-90$.

Arrow, K.J. and Hahn, F.H. (1971) General Competitive Analysis. San Francisco: Holden-Day, Inc.

Alvarez-Cuadrado, F. and Long, N.V. (2012) Envy and Inequality. The Scandinavian Journal of Economics 114, 949-73.

Banerjee, A. (1990) Envy, in B. Dutton et al (eds.), Economic Theory and Policy: Essays in Honor of Dipak Banerjee, Oxford: Oxford University Press.

Barro, R.J. and X. Sala-i-Martin (1995) Economic Growth. New York: McGraw-Hill, Inc.

Baumol, W. J. (1987) Superfairness: Applications and Theory. Cambridge, Massachusetts: MIT Press.

Brennan, G. (1973) Pareto Desirable Redistribution: The Case of Malice and Envy. Journal of Public Economics 2, 173-183.

Burmeister, E. and Dobell, A.R. (1970) Mathematical Theories of Economic Growth. London: Collier Macmillan Publishers.

Caselli, F. and Ventura, J. (2000) A Representative Consumer Theory of Distribution. American Economic Review 90, 909-26.

Debreu, G. (1959) Theory of Value: An Axiomatic Analysis of Equilibrium. Yale University Press, London.

Gershman, B. (2013) Envy in the Process of Development: Implications for Social Relations and Conflict. Economics of Peace and Security Journal 8, 13-19.

Gershman, B. (2014) The Two Sides of Envy. Journal of Economic Growth 19, 407-38.

Impicciatore, G., Panaccione, L., and Ruscitti, F. (2012) Walras' Theory of Capital Formation: An Intertemporal Equilibrium Reformation. Journal of Economic Theory 106, 99-118.

Jensen, B.S. and Larsen, M.E. (2005) General Equilibrium Dynamics of Multi-Sector Growth Models. Journal of Economics 10: 17-56.

Kirchsteiger, G. (1995) The Role of Envy in Ultimatum Games. Journal of Economic Behaviour and Organization 25, 373-89.

Mas-Colell, A., Whinston, M.D. and Green, J.R. (1995) Microeconomic Theory. New York: Oxford University Press.

Montesano, A. (2008) A Restatement of Walras' Theory of Capitalization and Money. History of Economics Review 47, 86-109.

Morishima, M. (1964) Equilibrium, Stability and Growth. Oxford: Oxford University Press.

Morishima, M. (1977) Walras' Economics. Cambridge: Cambridge University Press.

Mui, V.L. (1995) The Economics of Envy. Journal of Economic Behavior and Organization 26, 311-36.

Solow, R. (1956) A Contribution to the Theory of Growth. Quarterly Journal of Economics 70, 65-94.

Turnovsky, S.J. and Penalosa, C.G. (2006) Distributional Dynamics in a Neoclassical Growth Model: The Role of Elastic Labor Supply. Journal of Economic Dynamics Control 32, 1399-431.

Uzawa, H. (1961) On a Two-Sector Model of Economic Growth. Review of Economic Studies 29, 47-70. 
Revista Mexicana de Economía y Finanzas, Vol. 13 No. 4, (2018), pp. 507-523 523 DOI: http://dx.doi.org/10.21919/remef.v13i4.336

Varian, H. R. (1974) Equity, Envy, and Efficiency, Journal of Economic Theory 9, 63-91.

Walras, L. (1874) Elements of Pure Economics, translated from the French by W. Jaffé, 1954. London: Allen and Unwin.

Zhang, W.B. (1993) Woman's Labor Participation and Economic Growth - Creativity, Knowledge Utilization and Family Preference. Economics Letters 42, 105-10.

Zhang, W.B. (2005) Economic Growth Theory. Hampshire: Ashgate.

Zhang, W.B. (2012) Economic Growth with Heterogeneous Households, Gender Division of Labor, and Elastic Labor Supply. Journal of Income Distribution 21, 15-37.

Zhang, W.B. (2013) A Synthesis of the Uzawa-Lucas Model with the Walrasian-General-Equilibrium and Neoclassical-Growth Theories. Economic Annals 58, 8-38. 
524 REMEF (The Mexican Journal of Economics and Finance) 